\title{
Experimental Investigation of Transient Sublimator Performance
}

\author{
Rubik B. Sheth and Ryan A. Stephan \\ NASA Johnson Space Center \\ Thomas O. Leimkuehler \\ Paragon Space Development Corporation
}

\begin{abstract}
Sublimators have been used as heat rejection devices for a variety of space applications including the Apollo Lunar Module and the Extravehicular Mobility Unit (EMU). Sublimators typically operate with steady-state feedwater utilization at or near $100 \%$. However, sublimators are currently being considered to operate in a cyclical topping mode, which represents a new mode of operation for sublimators. Sublimators can be used as a topper during mission phases such as low lunar or low earth orbit. In these mission phases, the sublimator will be repeatedly started and stopped during each orbit to provide supplemental heat rejection for the portion of the orbit where the radiative sink temperature exceeds the system setpoint temperature. This paper will investigate the effects of these transient starts and stops on the feedwater utilization during various feedwater timing scenarios. The $\mathrm{X}-38$ sublimator and Contamination Insensitive Sublimator (CIS) were tested in a ground vacuum chamber to understand this behavior and to quantify the feedwater performance. Data from various scenarios will be analyzed to investigate feedwater utilization under the cyclical conditions. This paper will also provide recommendations for future sublimator designs and/or feedwater control.
\end{abstract}

